\title{
Screening for type 2 diabetes mellitus to prevent vascular complications: updated recommendations from the Canadian Task Force on Preventive Health Care
}

\section{Denice S. Feig, Valerie A. Palda, Lorraine Lipscombe, with the Canadian Task Force on Preventive Health Care}

An abridged version of this article appeared in the Jan. 18, 2005, issue of $C M A J$ and is available online at www.cmaj.ca/cgi/content/full/172/2/177/DC1

\section{Recommendations}

- There is fair evidence to recommend screening adults with hypertension for type 2 diabetes mellitus to prevent cardiovascular events and death (grade B recommendation).

- There is fair evidence to recommend screening adults with hyperlipidemia for type 2 diabetes to prevent cardiovascular events and death (grade $\mathrm{B}$ recommendation).

- There is good evidence to recommend lifestyle interventions for overweight individuals (body mass index $>25 \mathrm{~kg} / \mathrm{m}^{2}$, or $>22 \mathrm{~kg} / \mathrm{m}^{2}$ if of Asian descent) with impaired glucose tolerance to reduce the incidence of progression to diabetes (grade $B$ recommendation).

- There is fair evidence to recommend acarbose treatment for overweight individuals (as described above) with impaired glucose tolerance to prevent cardiovascular events and hypertension (grade B recommendation).

- There is insufficient evidence to recommend metformin or acarbose treatment for overweight individuals (as described above) with impaired glucose tolerance to prevent diabetes progression (grade I recommendation).
I $\mathrm{n}$ developing these recommendations, the Canadian Task Force on Preventive Health Care drew heavily on a recent systematic review prepared for the US Preventive Services Task Force of the evidence for screening asymptomatic people for type 2 diabetes mellitus to prevent cardiovascular events. ${ }^{1}$ That review was enhanced by the Canadian Task Force on Preventive Health Care in 2 ways: all new literature on screening was incorporated, and a separate systematic $\therefore$ review of the evidence related to the prevention of diabetes in people with impaired glucose tolerance was undertaken.

\section{Clinical considerations}

In patients who do not meet the above criteria, the decision to screen for diabetes or impaired glucose tolerance may be made on an individual basis. The decision to screen should hinge on an estimate of the patient's overall risk of cardiovascular disease (CVD). Patients whose overall risk would be raised by a diagnosis of diabetes to the extent that treatment would be changed (i.e., if the overall risk of CVD is raised to more than $10 \%$ ) may merit screening. Patients with other known CVD risk factors (e.g., smoking or increased age) may also benefit from screening for diabetes.

Screening involves only patients who are asymptomatic. Those who exhibit symptoms or signs of diabetes, or those who have potential complications associated with diabetes, should receive diagnostic testing.

Screening is best accomplished with a fasting plasma glucose test. Diabetes is diagnosed if the fasting plasma glucose level is $7.0 \mathrm{mmol} / \mathrm{L}$ or greater, or if the plasma glucose level is $11.1 \mathrm{mmol} / \mathrm{L}$ or greater in a 2-hour oral glucose tolerance test (OGTT). ${ }^{2}$ Either test should be done on 2 occasions before a diagnosis can be made. Impaired fasting glucose is diagnosed if the fasting glucose level is $6.1-6.9 \mathrm{mmol} / \mathrm{L}$, and $\mathrm{im}-$ paired glucose tolerance is diagnosed if the plasma glucose level is $7.8-11.0 \mathrm{mmol} / \mathrm{L}$ in a 2 -hour OGTT.

There is no information regarding the optimal screening frequency.

\section{Recommendations of others}

In its 2003 clinical practice guidelines the Canadian Diabetes Association recommends screening for diabetes with a fasting plasma glucose test every 3 years in people 40 years of age and older (grade: consensus). ${ }^{3}$ It recommends that screening be considered at an earlier age or be performed more frequently, or both, using a fasting glucose or 2-hour OGTT in people with additional risk factors for diabetes (grade: consensus). ${ }^{3}$

The American Diabetes Association recommends that patients, particularly those with a body mass index of $25 \mathrm{~kg} / \mathrm{m}^{2}$ or greater, be screened with a fasting glucose test every 3 years beginning at the age of 45 years. ${ }^{4} \mathrm{It}$, too, suggests that test- 
ing be considered at an earlier age or be carried out more frequently in people who are overweight if additional diabetes risk factors are present.

The US Preventive Services
Task Force found the evidence insufficient to recommend for or against routine screening of asymptomatic adults for type 2 diabetes, impaired glucose tolerance or impaired fasting glucose (grade I recommendation). ${ }^{5}$ It does, however, recommend screening for diabetes in adults with hypertension or hyperlipidemia (grade B recommendation).

\section{Evidence and clinical summary}

\section{The screening test}

Patients with asymptomatic diabetes in the preclinical phase can be reliably identified through screening. A fasting plasma glucose level of $7.0 \mathrm{mmol} / \mathrm{L}$ has moderate sensitivity $(40 \%-87 \%)$ but good specificity $(96 \%-99 \%)$ to predict a plasma glucose level of $11.1 \mathrm{mmol} / \mathrm{L}$ in a 2 hour OGTT. ${ }^{6-9}$ This level $(7.0 \mathrm{mmol} / \mathrm{L})$, like the level of $11.1 \mathrm{mmol} / \mathrm{L}$ in the 2-hour OGTT, has been shown to reflect a threshold separating patients who are at substantially increased risk of microvascular complications (e.g., retinopathy). ${ }^{2,10-12}$ Lowering the fasting plasma glucose threshold to $6.1 \mathrm{mmol} / \mathrm{L}$ improves the test's sensitivity $(66 \%-95 \%)$, but at the cost of specificity $(90 \%-96 \%){ }^{13}$ The OGTT, although considered the "gold standard," is more costly and time-consuming than the fasting plasma glucose test and is less reproducible. ${ }^{14}$

\section{Benefits of screening}

There is no direct evidence that screening for diabetes in the preclinical phase leads to benefit. Although there is good (level I) evidence that treatment with tight glycemic control in patients who have a clinical diagnosis of diabetes decreases the progression of microvascular complications after 10 years of treatment, benefits were seen only in intermediate outcomes (i.e., decreased progression of retinopathy and nephropathy), with a nonsignificant trend toward decreased rates of myocardial infarction..$^{15}$ Health outcomes such as death, cardiovascular events, blindness, end-stage renal disease and amputations were not reduced.

Therefore, early detection of diabetes through screening 5-6 years before clinical symptoms emerge in order to treat with tight glycemic control may not have a substantial incremental benefit over clinical diagnosis. With screened patients, presumably the gain during the first 15 years would be similar to or even less than that seen in diagnosed patients, given that their level of hyperglycemia would be milder in most cases. One could expect that the benefit might be translated into improved health outcomes in trials of longer duration. Improved health outcomes might also be demonstrated if treatment were started sooner; however, there is no evidence indicating this currently.

There is good (level I) evidence that treatment of hypertension $^{16-19}$ and hyperlipidemia ${ }^{20-30}$ in patients with diabetes decreases the incidence of cardiovascular events and cardiovascular-related death (macrovascular complications) within 5 years. Therefore, if one extrapolates this evidence to a screened population, early identification of diabetes in patients with hypertension or hyperlipidemia, and aggressive treatment, would have a substantial early benefit.

A targeted approach of screening only patients with hypertension or hyperlipidemia provides more certain benefit. In addition, it subjects fewer people to potential harms than does screening a broader population, because the number needed to screen in order to prevent 1 cardiovascular event over 5 years in a population with hypertension or hyperlipidemia is substantially lower than the number in the general population.

\section{Screening for impaired glucose tolerance}

Although there are studies suggesting a benefit of treating people who have impaired glucose tolerance to reduce the incidence of progression of diabetes and possibly cardiovascular disease, the evidence is still inadequate to recommend screening for impaired fasting glucose or impaired glucose tolerance. However, people with the latter condition may nonetheless be identified in the course of their health care. These patients should be treated with lifestyle interventions aimed at lowering weight and increasing exercise, because such interventions may lower the incidence of diabetes (level I evidence). ${ }^{31-33}$ Acarbose treatment can also be considered for these patients, because it has been shown to reduce the incidence of cardiovascular outcomes and hypertension (level I evidence). ${ }^{34}$ Although the use of metformin ${ }^{33}$ and acarbose ${ }^{35}$ in patients with impaired glucose tolerance has been shown to reduce the incidence of diabetes over 3 years, the rate of diabetes dropped when metformin was discontinued. ${ }^{36}$ Of note, the prevention trials were all of 3 to 6 years' duration, and it is unclear whether the effects of lifestyle or pharmacologic intervention persist beyond that period. Furthermore, it is still uncertain whether diabetes can truly be prevented or whether these strategies simply delay its onset. The impact of delaying diabetes for a few years on preventing microvascular complications would likely be small, since the risk of complications is low in the first 15 years after diabetes diagnosis. The beneficial effects of lifestyle modification on cardiovascular events in people with impaired glucose tolerance also remain to be demonstrated. Finally, the cost-effectiveness of screening for impaired glucose tolerance and offering lifestyle interventions only to those with a positive test result and not to all people with diabetes risk factors has not been examined.

\section{Potential harms of screening}

There has been little direct assessment of the potential harmful effects of screening for diabetes, and no decrease in quality of life has been associated with screening. ${ }^{37}$ The potential but unresearched harms of screening may include labelling, anxiety and altered self-perception, and loss of insurability. It has been estimated that in at least $30 \%$ of people who have positive impaired glucose tolerance or impaired fasting glucose test results, glucose levels revert to normal and diabetes never develops. ${ }^{38-44}$ 
Denice Feig is Associate Professor, University of Toronto, Department of Medicine, Division of Endocrinology and Metabolism, Mount Sinai Hospital; Valerie Palda is Assistant Professor, University of Toronto, Department of Medicine, Division of Internal Medicine, St. Michael's Hospital; Lorraine Lipscombe is Clinical Associate and Research Fellow, Department of Endocrinology, Sunnybrook and Women's College Health Sciences Centre, Toronto, Ont.

Competing interests: None declared for Valerie Palda or Lorraine Lipscombe. Denice Feig has received research funding from Novo Nordisk and an unrestricted educational grant from Aventis Pharma.

Contributors: Denice Feig and Valerie Palda reviewed the systematic review prepared for the US Task Force on Preventive Health Care, updated the literature on screening and wrote the technical report on which this article is based. Lorraine Lipscombe conducted the systematic review of prevention of diabetes in individuals with impaired glucose tolerance and wrote sections of the technical report related to that topic. Denice Feig drafted the recommendation statement; Lorraine Lipscombe and Valerie Palda reviewed drafts and made subsequent revisions. The Canadian Task Force on Preventive Health Care critically reviewed the evidence and developed the recommendations according to its methodology and consensus development process.

Acknowledgements: We thank Dr. Russel Harris for his valuable input and Ruth Walton for her helpful assistance in preparing this manuscript.

The Canadian Task Force on Preventive Health Care is funded by Health Canada.

This statement is based on the technical report: "Screening for type 2 diabetes to prevent vascular complications: updated recommendations from the Canadian Task Force on Preventive Health Care," by Denice Feig, Valerie A. Palda and Lorraine Lipscombe, with the Canadian Task Force on Preventive Health Care. The full technical report is available from the task force at ctf@ctfphc.org.

\section{References}

1. Harris R, Donahue K, Rathore SS, Frame P, Woolf SH, Lohr KN. Screening adults for type 2 diabetes: a review of the evidence for the U.S. Preventive Services Task Force. Ann Intern Med 2003;138(3):215-29.

2. Expert Committee on the Diagnosis and Classification of Diabetes Mellitus. Report of the Expert Committee on the Diagnosis and Classification of Diabetes Mellitus [ADA position paper]. Diabetes Care 2003;26(1):S5-20

3. Canadian Diabetes Association Expert Committee. Canadian Diabetes Association 2003 clinical practice guidelines for the prevention and management of diabetes in Canada. Screening and prevention. Can 7 Diabetes 2003;27(Suppl 2):S10-3.

4. American Diabetes Association. Screening for type 2 diabetes. Diabetes Care 2004;27(Suppl 1):S11-4.

5. US Preventive Services Task Force. Screening for type 2 diabetes mellitus in adults: recommendations and rationale. Ann Intern Med 2003;138(3): 212-4.

6. Blunt BA, Barrett-Connor E, Wingard DL. Evaluation of fasting plasma glucose as a screening test for NIDDM in older adults. Ranco Bernardo Study. Diabetes Care 1991;14:989-93.

7. Lee CH, Rook Chong S. Evaluation of fasting plasma glucose as a screening test for diabetes mellitus in Singaporean adults. Diabet Med 1997;14:119-22.

8. Chang CJ, Wu JS, Lu FH Lee HL, Yang YC, Wen MJ. Fasting plasma glucose in screening for diabetes in the Taiwanese population. Diabetes Care 1998;21:1856-60.

9. Wiener K. Fasting plasma glucose as a screening test for diabetes mellitus. Diabet Med 1997;14:711-2.

10. Bennett PH, Rushforth NB, Miller M, Lecompte PM. Epidemiologic studies of diabetes in Pima Indians. Recent Prog Horm Res 1976;32:333-76.

11. McCance DR, Hanson RL, Charles MA, Jacobsson LT, Pettitt DJ, Bennett PH, et al. Comparison of tests for glycated haemoglobin and fasting and two hour plasma glucose concentrations as diagnostic methods for diabetes [published erratum in $B M 7$ 1994:309:841]. BM7 1994:308:1323-8.

12. Engelgau MM, Thompson TJ, Herman WH, Boyle JP, Aubert RE, Kenny SJ, et al. Comparison of fasting and 2-hour glucose and $\mathrm{HbA}_{1 \mathrm{c}}$ levels for diagnosing diabetes; diagnostic criteria and performance revisited. Diabetes Care 1997;20:785-91.

13. Engelgau M, Narayan KNV, Herman $W$. Screening for type 2 diabetes. $D i$ abetes Care 2000;23:1563-80.

14. Mooy JM, Grootenhuis PA, de Vries H, Kostense PJ, Popp-Snijders C, Bouter LM, et al. Intra-individual variation of glucose, specific insulin and proinsulin concentrations measured by two oral glucose tolerance test in a general Caucasian population; the Hoorn Study. Diabetologia 1996;39:298-305.

15. UKPDS 33. Intensive blood-glucose control with sulphonylureas or insulin compared with conventional treatment and risk of complications in patients with type 2 diabetes (UKPDS 33). UK Prospective Diabetes Study (UKPDS) Group. Lancet 1998;352:837-53.

16. Hansson L, Zanchetti A, Carruthers SG, Dahlof B, Elmfeldt D, Julius S, et al. Effects of intensive blood-pressure lowering and low-dose aspirin in patients with hypertension: principal results of the Hypertension Optimal Treatment (HOT) randomized trial. Lancet 1998;351:1755-62.

17. UKPDS 38. Tight blood pressure control and risk of macrovascular and microvascular complications in type 2 diabetes. BM7 1998;317:703-13.

18. Schrier RW, Estacio RO, Esler A, Mehler P. Effects of aggressive blood pressure control in normotensive type 2 diabetic patients on albuminuria, retinopathy and strokes. Kidney Int 2002;61:1086-97.

19. Estacio RO, Jeffers BW, Gifford N, Schrier RW. Effect of blood pressure control on diabetic microvascular complications in patients with hypertension and type 2 diabetes. Diabetes Care 2000;23(Suppl 2):B54-B64.

20. Pyorala K, Pedersen TR, Kjekshus J, Faergeman O, Olsson AG, Thorgeirsson G. Cholesterol lowering with simvastatin improves prognosis of diabetic patients with coronary heart disease. A subgroup analysis of the Scandinavian Simvastatin Survival Study (4S). Diabetes Care 1997;20:614-20.

21. Koskinen P, Manttari M, Manninen $\mathrm{V}$, Huttunen JK, Heinonen OP, Frick $\mathrm{MH}$. Coronary heart disease inci- dence in NIDDM patients in the Helsinki Heart Study. Diabetes Care 1992;15:820-5.

22. Frick MH, Elo O, Haapa K, Heinonen OP, Heinsalmi P, Helo P, et al. Helsinki Heart Study: primary prevention trial with gemfibrozil in middle-aged men with dyslipidemia. $N$ Engl 7 Med 1987;317:1237-45.

23. Long-Term Intervention with Pravastatin in Ischaemic Disease (LIPID) Study Group. Prevention of cardiovascular events and death with pravastatin in patients with coronary heart disease and a broad range of initial cholesterol levels. N Engl 7 Med 1998;339:1349-57

24. Downs JR, Clearfield M, Weis S, Whitney E, Shapiro DR, Beere PA, et al. Primary prevention of acute coronary events with lovastatin in men and women with average cholesterol levels: results of AFCAPS/TexCAPS. Air Force/Texas Coronary Atherosclerosis Prevention Study. 7AMA 1998;279:1615-22.

25. Rubins HB, Robins SJ, Collins D, Fye CL, Anderson JW, Elam MB, et al. Gemfibrozil for secondary prevention of coronary heart disease in men with low levels of high-density lipoprotein cholesterol. Veterans Affairs HighDensity Lipoprotein Cholesterol Intervention Trial Study Group. $N$ Engl 7 Med 1999;341:410-8

26. Haffner SM, Alexander CM, Cook TJ, Boccuzzi SJ, Musliner TA, Pedersen TR, et al. Reduced coronary events in simvastatin-treated patients with coronary heart disease and diabetes or impaired fasting glucose levels: subgroup analysis in the Scandinavian Simvastatin Survival Study. Arch Intern Med 1999;159:2661-7.

27. Pignone MP, Phillips CJ, Atkins D, Teutsch SM, Mulrow CD, Lohr KN. Screening and treating adults for lipid disorders. Am 7 Prev Med 2001;20 (Suppl 3):77-89.

28. MRC/BHF Heart Protection Study of cholesterol lowering with simvastatin in 20,536 high-risk individuals: a randomised placebo-controlled trial. Lancet 2002;360:7-22.

29. Robins SJ, Collins D, Wittes JT, $\mathrm{Pa}$ pademetriou V, Deedwania PC, Schaefer EJ, et al. Relation of gemfibrozil treatment and lipid levels with major coronary events: VA-HIT: a randomized controlled trial. $7 A M A$ 2001;285:1585-91.

30. Goldberg RB, Mellies MJ, Sacks FM, Moy LA, Howard BV, Howard WJ, et al. Cardiovascular events and their reduction with pravastatin in diabetic and glucose-intolerant myocardial infarction survivors with average cholesterol levels; subgroup analyses and the Cholesterol and Recurrent Events (CARE) trial. The CARE investigators. Circulation 1998;98:2513-9.

31. Pan XR, Li GW, Hu YH, Wang JX, Yang WY, An ZX, et al. Effects of diet and exercise in preventing NIDDM in people with impaired glucose tolerance: The Da Qing IGT and Diabetes Study. Diabetes Care 1997;20(4):537-44.

32. Tuomilehto J, Lindstrom J, Eriksson JG, Valle TT, Hamalainen H, IlanneParikka P, et al; Finnish Diabetes Prevention Study Group. Prevention of type 2 diabetes mellitus by changes in lifestyle among subjects with impaired glucose tolerance. $N$ Engl 7 Med 2001;344(18):1343-50.

33. Knowler WC, Barrett-Connor E, 
Fowler SE, Hamman RF, Lachin JM, Walker EA, et al; Diabetes Prevention Program Research Group. Reduction in the incidence of type 2 diabetes with lifestyle intervention or metformin. $N$ Engl 7 Med 2002;346(6):393-403.

34. Chiasson JL, Josse RG, Gomis R, Hanefeld M, Karasik A, Laakso M STOP-NIDDM Trial Research Group. Acarbose treatment and the risk of cardiovascular disease and hypertension in patients with impaired glucose tolerance: the STOP-NIDDM trial. FAMA 2003;290(4): 486-494.

35. Chiasson JL, Josse RG, Gomis R, Hanefeld M, Karasik A, Laakso M, STOP-NIDDM Trail Research Group. Acarbose for prevention of type 2 diabetes mellitus: the STOPNIDDM randomised trial. Lancet 2002;359:2072-7.

36. Diabetes Prevention Program Research Group. Effects of withdrawal from metformin on the development of diabetes in the diabetes prevention program. Diabetes Care 2003;26(4):977-80.

37. Edelman D, Olsen MK, Dudley TK, Harris AC, Oddone EZ. Impact of diabetes screening on quality of life. $D i$ abete Care 2002;25:1022-6.

38. Eriksson KE, Lindgarde F. Impaired glucose tolerance in a middle-aged male urban population: a whole new approach for identifying high-risk cases. Diabetologia 1990;33:526-31.

39. Yudkin JS, Alberti KGMM, McLarty DG, Swai ABM. Impaired glucose tolerance: Is it a risk factor for diabetes or a diagnostic ragbag? $B M \mathcal{F}$ 1990;301:397-401.

40. Balkau B, Eschwege E. Repeatability of the oral glucose tolerance test for the diagnosis of impaired glucose tolerance and diabetes mellitus. Diabetologia 1991;34:201-2.

41. Ramaiya KL, Swai ABM, McLarty DG, Kitange HM, Alberti KGMM. Improvement in glucose tolerance af ter one year of follow-up in a Hindu community in Africa. Diabet Res Clin Pract 1990;10:245-55. Kilima PM, Masuki G, Mtinangi BI, et al. Study in Tanzania of impaired glucose tolerance: Methodological myth? Diabetes 1991;40(4):516-20.

43. Bourn DM, Williams SM, Mann JI.
42. Swai AB, McLarty DG, Kitange HM,

Distinguishing between persistent and transient impaired glucose tolerance using a prediction model. Diabet Med 1992;9:744-8

44. Warram JH, Sigal RJ, Martin BC, Krolewski AS, Soeldner JS. Natural history of impaired glucose tolerance: follow-up at Joslin Clinic. Diabet Med 1996;13:S40-5

Correspondence to: Canadian Task Force on Preventive Health Care 117-100 Collip Circle, London ON N6G 4X8; fax 519 858-5112; ctf@ctfphc.org

Members of the Canadian Task Force on Preventive Health Care

Chair: Dr. John W. Feightner, Professor, Department of Family

Medicine, The University of Western Ontario, London, Ont.

Vice-Chair: Dr. Harriet MacMillan, Professor, Departments of Psychiatry and Behavioural Neurosciences and of Pediatrics, Offord Centre for Child Studies, McMaster University, Hamilton, Ont.

Members: Drs. Paul Bessette, Professeur titulaire, Département d'obstétrique-gynécologie, Université de Sherbrooke, Sherbrooke, Que.; R. Wayne Elford, Professor Emeritus, Department of Family Medicine, University of Calgary, Calgary, Alta.; Denice S. Feig, Associate Professor, Departments of Medicine, of Obstetrics and Gynecology, and of Health Policy Management and Evaluation, University of Toronto, Toronto, Ont.; Joanne Langley, Associate Professor, Departments of Pediatrics and of Community Health and Epidemiology, Dalhousie University, Halifax, NS; Valerie A. Palda, Assistant Professor, Departments of Medicine and of Health Policy Management and Evaluation, University of Toronto, Toronto, Ont.; Christopher Patterson, Professor, Division of Geriatric Medicine, Department of Medicine, McMaster University, Hamilton, Ont.; Bruce A. Reeder, Professor, Department of Community Health and Epidemiology, University of Saskatchewan, Saskatoon, Sask. Resource staff: Ruth Walton, Research Associate, Canadian Task Force on Preventive Health Care, Department of Family Medicine, The University of Western Ontario, London, Ont. 